\title{
An Empirical Study on the Dealers' Ordering Strategies for Batches and Amounts
}

\author{
Bingqun Cui \\ College of Economics and Management \\ Shandong Agricultural University \\ Tai'an, China
}

\begin{abstract}
As a decision maker of the behavior, the dealer will take different batch and bulk order strategy under the policy of different prices of manufacturers, so as to maximize their own profits. In this study, we use the real data of the dealers to empirically test the different ordering strategies adopted in the face of different manufacturers' price policies. The study found that when facing with the reward price policies, the dealers tend to adopt centralized ordering strategy with large amounts and small batches; but when facing with threatening price policies, the dealers tend to adopt frequent ordering strategy with small amounts and large batches. The research conclusion has a good reference value and reference meaning to guide the use of price policies for the management of business managers.
\end{abstract}

Keywords - dealers; amounts and batches; ordering strategies; price policies of manufactures

\section{INTRODUCTION}

With China's economy into the new normal, manufacturer cooperation and adopting strategies with each other has become the focus under the strategic backgrounds of "Supplyside Structural Reform" and "Made in China 2025" in China. Fierce market competition promotes manufacturer enterprises to implement various price policies for their sales channels and cooperative clients so as to stabilize the channels, promote the growth of sales and expand market share. A survey about the interviews carried out for manufactures and dealer enterprises of China's new construction materials industries showed that more than $80 \%$ manufacturers will take various forms of price policies for their dealers or retailers, and when facing the price policies of manufacturers, more than $60 \%$ dealers will respond positively and increase their orderings. At the same time, different dealers will also use different ordering strategies to deal with in the face of different price policies of manufacturers, so that maximizing their own profits.

So what kinds of ordering strategies will dealers take when they face different price policies launched by manufacturers? What revelation and helps can be brought from these strategies to the use of price policies and channels management of manufacturers? Based on the relevant theories, this paper will study the different changes of the ordering strategies with amounts and batches when the dealers face the different price policies.

\section{THEORETICAL REVIEW AND RESEARCH HYPOTHESES}

\section{A. Ordering Strategies with Amounts and Batches}

Generally speaking, these two words "amounts and batches" are from the control research of products production process, are generated with the great improvement of production efficiency, the shortening of processing cycle and the improvement of the degree of automation for the industries in the industrial revolution. And they are widely used in lean production, inventory problem and supply chain. Chand S. [3] and Goyal S K.[4] had studied the ordering ways with economic amounts model. The research proved that the ordering amounts had a significant influence on the entire production inventory, and put forward the relevant ordering strategies. The research of Park K S.[5] analyzed the assignment of amounts in the transportation industry with using economic amounts model and taking the transportation industry as the background. In this study, the conception of amounts and batches were introduced aiming at studying the ordering strategies with amounts and batches when dealers faced the different price police of manufacturers. In view of the above, we can divide the ordering strategies with amounts and batches of the dealers into the centralized ordering strategies with large amounts and small batches and small batch and the frequent ordering strategies with small amounts and large batches. In the face of different price policies of manufacturers, dealers choose to take two different ordering strategies with the purpose of ensuring a reasonable inventory and meeting the demands of downstream clients, which is basically for profits and economics.

\section{B. Behavior Decision and Price Policy Theories}

The prospect theory proposed by Kahneman and Tversky (1979)[6] was an important theory of descriptive behavior decision. According to the prospect theory, when the individual is making the decision, this process will go through two stages that one is to describe the decision and establish the reference point, and another is to obtain the expected total utility through evaluation. The response to the expected "loss" is more sensitive than the response to the expected "earnings", that is, as for the clients, the response that the price is higher than the reference point is greater than the response that the price is lower than the reference point. The price function also points out that the behavior decision made by people under the 
condition of uncertain risks has three characteristics, namely risk aversion, reference point effect and diminishing marginal utility.

The price policy is an important part of the marketing mix and is a means that manufacturers or channel participants improve customer values and stimulate purchases of clients through reducing the price of a brand product or increasing the number of commodities with fixed price in a specific period of time[7]. In the practice of the manufacturer to dealer's price policy, there are two different price policies: one is the "reward price policy" refers that if the dealers order the specified products in a certain period, they can enjoy price concessions in a certain proportion or in figure; another is the "threatening price policy", refers that the manufacturers notify the dealers in advance to order the specified products after a specified time, the price will be rose in a certain proportion or in figure.

\section{Research Hypotheses}

Based on the price policy and prospect theory, the "reward price policy" means that manufacturers directly make price concessions, which brings the dealer's perception that to order the products specialized by manufacturers will gain the "earnings"; and the "threatening price policy" brings the dealer's perception that to order the products in a certain date will increase the "loss". During the reward strategy, the ordering price of the specified products is lower than the reference price, and the dealers will feel that they have gained much utility, and the transaction is more cost-effective, so they will increase the single ordering amounts. At the same time, prospect theory proposed that under the condition of uncertain risks, the decision behavior of decision makers often show the characteristic of "risk aversion", because at the risk of uncertain decision behavior under the condition, because the "threatening price policy" means that the price will rise when the dealers order this product in a certain period of time in the future, but at present, ordering the products will not cause the "loss"; and at the same time, as it is limited by the customer's fixed storage capacity, if the clients once decide to order, it will present more frequent ordering tendency under the threatening sales promotion. According to the characteristic of "diminishing marginal utility" presented by decision behavior under the condition of uncertain risks, in the face of the "reward price policy", the clients will increase the somg;e ordering amounts; but due to the fixed limitation of storage capacity, the frequency will decrease. And due to the under the influence of the reference point, the psychological feelings of the "earnings" and "loss" are different; as for earnings, the clients tend to choose the defined results; and as for loss, the clients generally tend to choose risk. As a result, once the clients decide to order, they respond to the threatening strategy more strongly and are likely to order more frequently.

Because the inventory sizes of dealers are different, it will lead to different inventory holding costs between dealers. So when facing the price discrimination carried out by manufacturers through price sales promotion strategy, dealers can adopt different ordering strategies to profit according to their own inventory holding cost. According to the above reasoning, under the threatening strategy, the number of times of dealers' ordering are significantly higher than that of the reward strategy, showing the behavior tendency of frequently ordering; while under the reward strategy, the single ordering amount of dealers is higher than that of the threatening sales promotion; and the reason that this ordering tendency is widely different is that the dealers have taken a different ordering strategies according to their own inventory holding cost.

Based on the above reasoning, the following hypotheses are put forward:

H1: Under the award price policy, dealers tend to adopt centralized ordering strategy with large amounts and small batches;

$\mathrm{H} 2$ : Under the threatening price policy, dealers tend to adopt frequent ordering strategy with small amounts and large batches.

\section{Research Framework}

This research focuses on the change of the ordering strategies caused by the change of the dealers' ordering behavior, and respectively tests the effects of award price policy and threatening price policy on the dealers' single ordering amount and single ordering times. At the same time, considering that the dealers' single ordering amount and ordering times may be affected by other factors, in order to control these effects, the study chooses the duration of policy, dealers' scale, year, season, region and product as control variables into the model, and on the basis of controlling their effects, the study tests the effect of sales promotion strategies on the dealers' ordering strategies. The conceptual framework of this study is shown in "Fig. 1".

\section{Price Polices of Manufacturers Ordering Strategy of Dealers Control Variables}

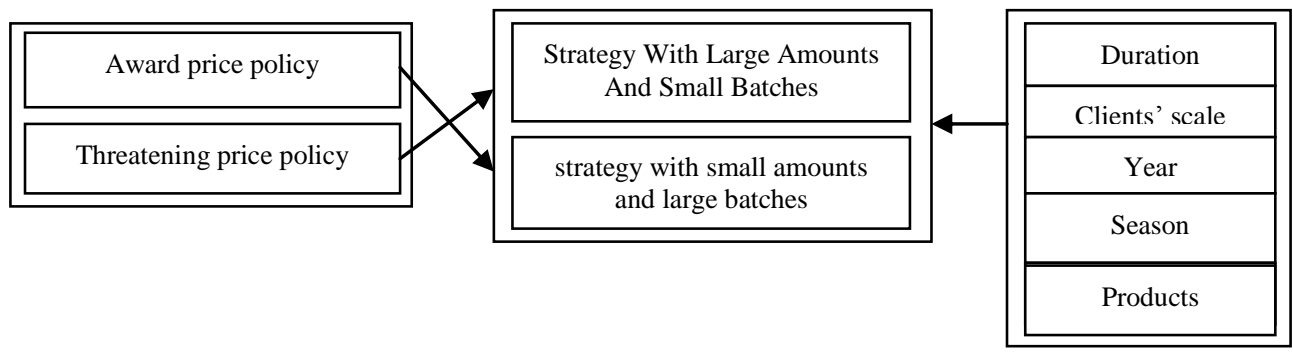

Fig. 1. Conceptual framework 


\section{RESEARCH DESIGN}

\section{A. Data and Measurement}

This study has selected the subordinate dealer of some manufacturer of new building materials industry in China as the object of data collection and selected a total of 348 dealers in Beijing, Tianjin, Hebei, Sichuan, Chongqing and other places as the sample data. This study has obtained a complete record that this manufacturer implemented price policies for 348 dealers during January 1, 2011 to June 30, 2013 from the internal sales database of enterprises and also has obtained all sales data for these dealers. The dealers in the sample account for $59 \%$ of the southwest, $41 \%$ of the North China, with the average annual sales of 17.7 million yuan.

TABLE I. DESCRIPTIVE StATistics OF DATA

\begin{tabular}{|c|c|c|c|c|c|c|}
\hline Variables & $\begin{array}{l}\text { Sample } \\
\text { number }\end{array}$ & $\begin{array}{c}\text { Average } \\
\text { value }\end{array}$ & $\begin{array}{l}\text { Standard } \\
\text { deviation }\end{array}$ & Minimum & Maximum & $\begin{array}{c}\text { Other } \\
\text { indicators }\end{array}$ \\
\hline \multicolumn{7}{|l|}{ Clients' characteristics } \\
\hline North China & 144 & - & - & - & - & - \\
\hline Southwest & 204 & - & - & - & - & - \\
\hline Sales scale of dealers (Ten thousand yuan) & 348 & 1770 & 14358 & 32 & 268000 & - \\
\hline \multicolumn{7}{|l|}{ Price policies } \\
\hline Intensity of strategies & 1803 & 0.19 & 0.08 & 0.02 & 0.40 & - \\
\hline Award price policy & 1660 & 0.20 & 0.08 & 0.05 & 0.40 & - \\
\hline Threatening price policy & 143 & 0.08 & 0.03 & 0.02 & 0.10 & - \\
\hline Duration & 1803 & 14 & 26 & 3 & 302 & - \\
\hline Award price policy & 1660 & 13 & 24 & 3 & 302 & - \\
\hline Threatening price policy & 143 & 30 & 32 & 4 & 208 & - \\
\hline
\end{tabular}

a. a Through the questionnaires conducted by clients, sales scale of dealers can gain the average annual sales data (to count all sales products of clients, including but not limited to the products of the company), and the

\section{B. Research Method}

In the face of the manufacturer's price policy, the strategy changes of the dealer's ordering strategy ultimately embody in the changes of total amounts of ordering. Whether it adopts centralized ordering strategy with large amounts and small batches or frequent ordering strategy with small amounts and large batches, they are both realized through acting on the changes of single ordering amounts and single ordering times of dealers. Therefore, this study respectively constructs "single ordering amounts model" and "single ordering form amounts model" based on the single ordering amounts and single ordering form amounts (ordering times) of dealers. In the "single ordering amounts model", the ordering amount is as the dependent variable. The dealer's single ordering amounts record the ordering amount that the dealer every places order at a time. Single ordering amount model analyzes the influence of the each related variable on it, and we use log-linear regression to analyze so that the effect of many independent variables that influence single ordering amounts can be presented with the percentage of changes of purchases to make the measurement of effect more direct. In the "single ordering form amounts model", the ordering form amounts (ordering times) of clients are used for measuring the frequent extent of ordering. Cameron and Trivedi (1998) [8] pointed out that the model that considers the occurrence times of random event as the dependent variable usually used count-based regression model to analyze. The count-based regression model is based on Poisson regression model that Poisson distribution is a kind of probability distribution that is used for describing the occurrence times of random event in unit time or space. The Poisson regression model has an important hypothesis that the expectation of the dependent variable should be equal to the variance. In this study, the average value of the ordering form amounts is far less than the variance in the implementation of the price policy, and this phenomenon is called the over- discretization phenomenon, which usually uses negative binomial regression to analyze [8]. The main reason that the ordering form shows the over-discretization phenomenon is that the dealer does not have any ordering behavior for the specialized products or has many examples with no ordering times during the period of the implementation of the price policy for many times. This paper adopts Hurdle [9] [10] regression model to analyze the influence of price policies on the ordering times (ordering amounts); and uses logistic regression as the selection of discretization in the hurdle model to analyze the influence of different price policies on whether the dealer will order; and as for the clients who decide to order, uses count-based regression model, and uses negative binomial regression to modify the underestimate of Poisson model for the actual variation level of data, and to analyze the influence of price sales promotion strategy on ordering times (frequent ordering tendency) of clients.

\section{EMPIRICAL ANALYSIS}

\section{A. Dealers' Ordering Amount Model at a Time}

This study (see Table 2) adopts multiple linear regression to analyze the influences of the dealer's single ordering amounts affected by two price policies, and the goodness of fit $\mathrm{R} 2$ of the model is about 0.3 , which shows that the model can explain the effect of price policy to some extent. The performance of the control variables is in line with expectations. There is a significant negative correlation between the product's unit price and the ordering amounts of the dealer, and there is a significant positive correlation between the dealer's sales scale and the dealer's ordering amounts. And there is no significant difference between different models in the strength of the relationship between the both, indicating that the role of the control variables is relatively stable, and plays a role in controlling other unrelated 
effects. The model represents the influence of the award price policy and threatening price policy on the ordering amounts of dealers. It can be seen from table 1 that after controlling other factors that may affect the ordering amounts, the reward strategy has an positive effect on the ordering amounts of dealers $(\beta=1.176, p<0.001)$, while the threatening strategy has an negative impact on the ordering amounts of dealers $(\beta=$ $1.296 \mathrm{p}<0.001)$. Calculated according to the characteristics of the log-linear model, for the award strategy, if the strength of price reduction increases a percentage, the purchases of dealers will increase 1.1 percentages; and for the threatening strategy, if the range of markup increases a percentage, the ordering amounts of dealers will fall 1.2 percentages. The results show that the dealer will increase the single ordering amounts with the increase of the strength of price reduction, and reduce the single ordering amounts with the increase of the range of markup of the threatening strategy.

TABLE II. DEALER'S SingLE ORDERING AMOUNTS MODEL

\begin{tabular}{|c|c|}
\hline $\begin{array}{c}\begin{array}{c}\text { Ordering amounts (Natural } \\
\text { logarithm value) }\end{array} \\
\end{array}$ & Model \\
\hline Intercept & $\begin{array}{l}6.680 * * * \\
(.275)\end{array}$ \\
\hline Award price policy & $\begin{array}{l}1.179 * * * \\
(.057)\end{array}$ \\
\hline Threatening price policy & $\begin{array}{l}-1.228^{* * *} \\
(.095)\end{array}$ \\
\hline Unit price of products & $\begin{array}{l}-.108 * * * \\
(.006) \\
\end{array}$ \\
\hline $\begin{array}{lll}\text { Sales scale of dealers } & \text { (Natural } \\
\text { logarithm value) } & & \\
\end{array}$ & $\begin{array}{l}.105 * * * \\
(.004)\end{array}$ \\
\hline Year & Controlling \\
\hline Season & Controlling \\
\hline Products & Controlling \\
\hline Region & Controlling \\
\hline $\mathrm{R} 2$ & .297 \\
\hline Adjusting R2 & .297 \\
\hline The number of sample & 87497 \\
\hline
\end{tabular}

\section{B. Dealers' Ordering Times Model}

This study (see Table 3) uses the Hurdle model [23, 24] to respectively analyze whether the dealer will order and the ordering times in the implementation of a single price policy, and to measure the overall effect of price policy on the ordering times of dealers with a total measurement of the ordering times of dealers who have benefited from the price policy in the implementation of the price policy during January 1, 2011 to June 30, 2013. From the view of the control variables, the longer the duration is, the more possibly dealers order at least once $(\beta=0.011, \mathrm{p}<0.001)$, and the more frequently clients order $(\beta=0.021, \mathrm{p}<0.001)$, which is consistent with the hypothesis of the duration and ordering behavior carried out by this study. The client's sales scale is also consistent with the hypothesis, that is the stronger of the strength the clients have, the more possibly they will order $(\beta=$ $0.194, \mathrm{p}<0.001)$, and the more frequently clients order $(\beta=$
0.289, $\mathrm{p}<0.001)$. The model shows that from in general, comparing the reward strategy with the threatening strategy, dealers are more likely to choose to order in the former state $(\beta=0.200, p<0.001)$, but in the dealers who have decided to order, the manifestation of ordering times is on the contrary, that is comparing the reward strategy, the threatening strategy will bring much ordering times $(\beta=-0.171, \mathrm{p}<0.05)$, which has verified the different reactions when decision makers face "profits" and "loss".

TABLE III. DEALERS' ORDERING TIMES MODEL

\begin{tabular}{|l|l|}
\hline \multicolumn{1}{|c|}{$\begin{array}{c}\text { Variables (the ordering form } \\
\text { amounts) }\end{array}$} & \multicolumn{1}{|c|}{ Model } \\
\hline Logit's regression coefficient & $-6.271^{* * *}$ \\
\hline Intercept & $.212)$ \\
\hline Duration & $.011^{* * *}$ \\
& $(.001)$ \\
\hline Price policy (Award price policy) & $.200^{* * *}$ \\
& $(.054)$ \\
\hline $\begin{array}{l}\text { Sales scale of dealers (Natural } \\
\text { logarithm value) }\end{array}$ & $.194^{* * *}$ \\
\hline Year & Controlling \\
\hline Season & Controlling \\
\hline Products & Controlling \\
\hline Region & Controlling \\
\hline Negative binomial regression & \\
coefficient & \\
\hline Intercept & $-2.930^{* * * *}$ \\
& $(.349)$ \\
\hline Duration & $.021^{* * *}$ \\
& $(.001)$ \\
\hline Price policy (Award price policy) & $-.171^{*}$ \\
& $(.083)$ \\
\hline Sales scale of dealers (Natural & $.289^{* * *}$ \\
logarithm value) & $(.021)$ \\
\hline Year & Controlling \\
\hline Season & Controlling \\
\hline Products & Controlling \\
\hline Region & Controlling \\
\hline Log (Dispersion degree) & $-1.155^{* * *}$ \\
& $(.066)$ \\
\hline Log-likelihood value & -34257 \\
\hline The number of sample & 45096 \\
\hline & According to the above empina \\
\hline
\end{tabular}

According to the above empirical analysis, under normal circumstances, the price policy will bring the improvement of dealers' ordering willingness, and then the ordering behavior will change. This increase of ordering willingness will influence the ordering behavior of dealers in the roles of two aspects: one is the price policy reduces the price threshold, the stimulating effect that it brings makes the dealer who was not willing to order choose to order now, or make the dealer who was willing to order frequently order now, which plays a role in promoting dealers to increase the ordering form amounts. On the other hand, in a single ordering amount, due to the role of the expected "benefits", the price policy may bring an increase in the single ordering amounts of dealers. The common change of the ordering amount and the single ordering amount constitutes the different ordering policies of dealers for the different sales promotion strategies. In the dealers' ordering times model, comparing the award strategy with the threatening strategy, the impact of ordering times is negative in the eyes of dealers who have ordered, that is comparing the reward strategy with the threatening strategy, 
dealers tend to be less ordering times. In the dealers' single ordering amount model, the award strategy can increase the single ordering amounts of dealers, but the threatening strategy can reduce the ordering amounts of dealers. This implies that under the different price policies, the ordering behaviors taken by dealers are very different. That is to say during the period of the award price policy, dealers tend to adopt centralized ordering strategy with large amounts and small batches; but during the period of the threatening strategy, dealers tend to adopt frequent ordering strategy with small amounts and large batches. Therefore, the $\mathrm{H} 1$ and the $\mathrm{H} 2$ in the study's hypotheses are both validated.

\section{CONCLUSION}

This study verifies the impacts of the award price policy and threatening price policy on the dealer's ordering strategies. The results of this study show that under the award strategy, dealers tend to adopt centralized ordering strategy with large amounts and small batches; while under the threatening strategy, dealers tend to adopt frequent ordering strategy with small amounts and large batches. As a kind of effective incentive sales measure, price policies are widely used by manufacturers. Due to the limitations of different storage holding costs caused by dealers' different strengths and different storage capacity, when facing the price discrimination carried out by manufacturers through price sales promotion strategy, dealers will adopt different ordering strategies through adjusting the frequency of ordering and the single ordering amounts so as to obtain higher profits.

With China's economy into the new normal, the market competition has been increasingly fierce. As an important marketing tool that manufacturers promote the growth of sales, price policies are widely used in the marketing practices. This study greatly enriches the studies of price policies, channel sales promotion and other marketing theories, and provides valuable empirical evidences for manufacturers who adopt different price policies according to different dealers. According to the actual situation of dealers' different inventory holding costs, dealers will respectively different ordering strategies with large amounts and small batches and small amounts and large batches, which provides a more effective reference for the enterprise managers who want to take more effective sales promotion strategy according to the specific circumstances of dealers.

\section{REFERENCES}

[1] Tony Haitao Cui, Jagmohan S. Raju, Z. John Zhang, A Price Discrimination Model of Trade Promotions[J]. Marketing science, 2008,27(9),779-795.

[2] Cui B.Q., Li Y.P. Research on Mechanism of Distributors' Frequent Ordering Intention: A Prospect Theory Perspective[J]. Modern Economy , 2015,(6),1167-1172.

[3] Chand S.,Ward J., A note on economic order quantity under conditions of Permissible delay in Payments [J].Journal of Operational Research Soeiety, 1987,38.

[4] Goyal S K., Economic order quantity under conditions of Permissible delay in Payments[J]. Journal of Operational Research Soeiety, 1985,36.

[5] Park K S., Fuzzy set theoretic interpretation of economic order quantity [J]. IEEE Transactions on systems, 1987,17.
[6] Kahneman D., Tverskey. A Prospect Theory: An analysis of decision under risk [J]. Econometrica, 1979,47(2): 263-291.

[7] Raghubir P., Corfman K. When Do Price Promotions Affect Pretrial Brand Evaluations? [J]. Journal of Marketing Research ,1999, 36 (2),211-222.

[8] Cameron A C, Trivedi P K. Regression analysis of count data [M]. Cambridge University Press, 1998.

[9] Mullahy J. Specification and testing of some modified count data models [J]. Journal of Econometrics, 1986,33(3): 341-365. 